\title{
POSSIBILITY OF GAMMA-INDUCED SENSIBILIZATION PROCESS IN RARE-EARTH DOPED YAG CRYSTALS
}

\author{
S. KaCzMareK ${ }^{a}$, A.O. MatKovskil ${ }^{b}$, Z. MierCZyK ${ }^{a}$, K. KopCZyński ${ }^{a}$, \\ D.Yu. Sugak ${ }^{b}$, A.N. Durygin ${ }^{c}$ AND Z. FrukaCZ ${ }^{d}$ \\ "Institute of Optoelectronics, MUT, 2 Kaliski Str., 01-489 Warsaw, Poland \\ "SRC "Carat", R\&D Institute of Materials \\ 202, Stryjska Str., 290031 Lviv, Ukraine \\ c Institute of Physics, Ukrainian Academy of Science \\ 46 Nauka Av., 252650, Kiev, Ukraine \\ d Institute of Electronic Materials Technology \\ 133 Wólczyńska Str., 01-919 Warsaw, Poland
}

The infuence of gamma irradiation on optical and lasing properties of Nd:YAG, Er:YAG and CTII:YAG single crystals was studied. The increase in optical output was established for rods without thermal annealing. The possible mechanisms of radiation sensibilization are discussed.

PACS numbers: 61.72.Ji, 61.80.Ed, 78.20.Dj

\section{Introduction}

It is well established that color centers (CCs) produced by ionizing radiation or short-wave radiation of the pump lamp, strongly influence the optical characteristics of yttrium-aluminium garnet (YAG) single crystals. Many publications, including reviews and monographs [1-3], are devoted to this problem. The most thoroughly investigated aspect was the influence of various types of ionizing radiation (gamma quanta, electrons, neutrons) on performance of YAG crystals activated with $\mathrm{Nd}$ ions [2].

The CCs, arising in the crystals, absorb not only pump light but also laser light, significantly increasing laser energy losses [4]. Creating losses at the laser wavelength [5], the CCs reduce the slope of efficiency. In Ref. [6] the improvement of performance of $\mathrm{Nd}: \mathrm{YAG}$ lasers was reported as an effect of small dose of gamma and electron irradiation.

During optical investigations of Nd:YAG crystals, particular attention was paid to $\mathrm{Cr}^{3+}$ ions, because they not only sensibilize the laser medium but, at certain concentrations, they may also reduce the susceptibility of YAG crystals to ionizing radiation effects [7]. 
In recent years, many new laser crystals came into market and took the important place. Among them are, for example $\mathrm{Er}_{3} \mathrm{Y}_{3} \mathrm{Al}_{5} \mathrm{O}_{12}$ (Er:YAG) and $\mathrm{Ho}, \mathrm{Tm}$, $\mathrm{Cr}: \mathrm{Y}_{3} \mathrm{Al}_{5} \mathrm{O}_{12}$ (CTH:YAG) crystals lasing in the bands of $2.94 \mu \mathrm{m}$ and $2.13 \mu \mathrm{m}$ interesting for medical applications [8]. The influence of gamma and short-wave radiation on optical properties of Er:YAG and CTII:YAG crystals has been presented in [9-11]. In Ref. [12] the authors examined the effect of the spectral composition of pump light on lasing and spectral-luminescence properties of $\mathrm{Y}_{3} \mathrm{Sc}_{2} \mathrm{Ga}_{3} \mathrm{O}_{12}$ and $\mathrm{Gd}_{3} \mathrm{Sc}_{2} \mathrm{Al}_{2} \mathrm{O}_{3}$ crystals activated with $\mathrm{Ho}, \mathrm{Tm}$ or $\mathrm{Cr}$ ions.

The present paper regards the effects of gamma radiation on optical characteristics of Er:YAG, CTH:YAG crystals as well as examinations of lasing characteristics of gamma irradiated active elements made from the above crystals. For comparison, optical characteristics of Nd:YAG crystals are also presented.

\section{Experimental setup \\ 2.1. Crystal growth}

The examined crystals were pulled by Czochralski technique from iridium crucibles in $\mathrm{N}_{2}$ atmosphere (for YAG, Nd:YAG, Er:YAG, and CTH:YAG). The concentration of $\mathrm{Nd}$ in the crystals were of the order of 1 at.\%. The concentration of erbium in the Er:YAG crystals was equal to 33 at.\%, which corresponds to the formula of $\mathrm{Y}_{2} \mathrm{ErAl}_{5} \mathrm{O}_{12}$. The composition of the CTH:YAG crystals conformed to the formula

$$
\left(\mathrm{Y}_{1-x-y} \mathrm{Ho}_{x} \mathrm{Tm}_{y}\right)_{3}\left(\mathrm{Al}_{1-z} \mathrm{Cr}_{z}\right)_{5} \mathrm{O}_{12}
$$

where $x=0.0036, y=0.057, z=0.01$. The detailed description of the applied growth process of the crystals is presented in the papers [13-15].

\subsection{Radiation source}

Gamma ray irradiation of the samples was performed with ${ }^{60} \mathrm{Co}$ source at a rate of $170 \mathrm{rads} / \mathrm{s}$ and dosage levels of the order of $10^{2}-10^{5} \mathrm{~Gy}(1.25 \mathrm{MeV})$.

\subsection{Spectroscopic investigations}

In order to obtain the absorption coefficients in the range of 200 to $1100 \mathrm{~nm}$, transmission spectra of the samples were taken using LAMBDA-2 Perkin-Elmer spectrometer.

Samples of YAG doped with Nd (1 at.\%), Cr, Tm, Ho (0.36 at.\% Ho, 5.7 at.\% Tm and 1 at.\% Cr) and $\operatorname{Er}(33$ at.\%), with diameters of $10 \mathrm{~mm}$ and thickness of 1-2 $\mathrm{mm}$ were cut out perpendicularly to the growth axis in the plane (111) from the most homogeneous parts of crystals. After optical polishing of both ends, the crystals were examined with Mach-Zehnder interferometer system. These samples were similar in quality to the laser crystals.

\subsection{Lasing investigations}

To measure the gamma radiation effects on the optical output of Er:YAG crystal, an active rod of $5 \mathrm{~mm}$ in diameter and $85 \mathrm{~mm}$ in length was used. The rod 
was not subjected to preliminary thermal annealing and it had no anti-reflection (AR) coatings on its end faces. The detailed characteristics of the rod, designated as E21, are presented in [13].

In the case of CTH:YAG crystals two different samples were examined. The active rod, denoted as G21, with the diametcr of $4 \mathrm{~mm}$ and length of $63 \mathrm{~mm}$, was not thermally annealed. The second rod, denoted as G32, with the diameter of $4 \mathrm{~mm}$ and length of $67 \mathrm{~mm}$ was annealed in oxidizing atmosphere at $1500^{\circ} \mathrm{C}$. The end faces of the rods were not AR coated. The designations of the rods correspond to those in the paper [14], where their lasing characteristics are also presented.

To measure the optical output of Er:YAG and CTH:YAG rods, a plane-parallel resonator of $19 \mathrm{~cm}$ in length was used. The transmissions of output mirrors were equal to $20 \%$ for CTH:YAG rods and $30 \%$ for Er:YAG rods. The examinations were carried out in the ellipsoidal reflective head made of gold-covered brass. The pump was a xenon arc lamp of $4 \mathrm{~mm}$ in diameter, charged to $0.5-2.5 \mathrm{kV}$ of voltage with $160 \mu \mathrm{F}$ capacitor battery. Pulse duration of the lamp equals to about $300-580 \mu \mathrm{s}$. The laser light was detected with high-sensitive HgCdTe photoconductor and time characteristics of the lamp were observed with the use of $\mathrm{Si}$ photodiode. The energy of laser pulses was measured by Gen-Tec radiometer with ED-500 gauge head.

\section{Results and discussion}

\subsection{Optical properties}

The short-wave edge of absorption spectrum of Er:YAG crystals approaches $193 \mathrm{~nm}$. Some absorption bands caused by intracenter transitions in $\mathbf{E r}^{\mathbf{3 +}}$ ions are placed within their transparent region. UV irradiation effects in the investigated crystals were reported in the paper [10]. Generally, in the samples there appear the same additional absorption bands as those after gamma irradiation, but CCs created by UV are unstable at room temperature. Moreover, what is very important for laser application of gamma irradiated Er:YAG crystals, those crystals show a weak susceptibility to UV radiation (UV additional absorption values of the order of $\left.0.2 \mathrm{~cm}^{-1}\right)$.

After gamma irradiation, a wide, complex additional absorption (AA) band appears within the range of 200-930 $\mathrm{mm}$. The peaks of absorption are placed in the surroundings of $240,310,400$ and $625 \mathrm{~mm}$. With the increase in gamma irradiation dosage level from $10^{2}$ to $10^{4} \mathrm{~Gy}$, the $\mathrm{AA}$ values grow larger and larger and become saturated for dosage levels of $10^{4}-10^{6} \mathrm{~Gy}$. It may be noticed that the gamma-induced absorption spectrum of Nd:YAG crystals has got a similar form as that of Er:YAG crystals and nearly the same peaks can be distinguished in both spectra. The same shape and position of the AA peaks is observed in spectrum for nominally pure YAG crystals. The greatest increase in the absorption intensity indicates a higher concentration of CCs in the undoped material.

It should be stated that the AA spectrum of Er:YAG crystals, measured during our examinations, slightly differs from that described in the paper [9] for the Er:YAG crystal grown in the inertial atmosphere and irradiated by UV pump lamp. After the UV irradiation, the maximum of $A A$ was observed at $\approx 310 \mathrm{~nm}$ 
and the total intensity of $\Lambda A$ was reduced more than five times. For crystals grown in vacuum and irradiated with $U V$ light, the intensity of $A A$ at $\approx 380 \mathrm{~nm}$ increases considerably.

The analysis of the published reports on radiation-induced coloring of YAG and Nd:YAG crystals [3] shows that the form and intensity of AA spectrum depends, in large degree, on the growth conditions of crystals (method and atmosphere of growth, purity of starting material, addition of an activator etc.). At the same time, in some papers $[16,17]$, the existence of specified $A \Lambda$ bands placed in $240-250 \mathrm{~nm}, \approx 310 \mathrm{~nm}$ and $\approx 380-450 \mathrm{~nm}$ regions is reported. The bands within the $240-250 \mathrm{~nm}$ range are usually explained as caused by absorption of non-controlled $\mathrm{Fe}^{3+}$ impurities. The band placed near $310 \mathrm{~nm}$ is attributed mostly to the absorption of $\mathrm{Fe}^{2+}$ ions, but probable the CCs comnected with oxygen vacancies make a contribution to it. The absorption bands within the $380-450 \mathrm{~nm}$ range are interpreted as the influence of $\mathrm{O}^{-}$hole centers, localized near defects of cation sublattice.

Consequently, it can be assumed that the AA bands observed in gamma-irradiated Er:YAG crystals are connected with, stable at room temperature, CCs produced by gamma-induced recharging of growth defects, for example non-controlled impurities of $\mathrm{Fe}$ ions, oxygen vacancies or defects of cation sublattice (rare-earth ions instead of $\mathrm{Al}^{3+}$ ions). As a matter of fact, the precise definition of nature of the CCs demands more detailed investigations [5].

To measure the thermal stability of optical property changes caused by irradiation, an isochronous annealing of irradiated samples was performed in temperatures $293-673 \mathrm{~K}$ ( $15 \mathrm{~min}$ duration at each temperature with steps of 20-30 K). The increase in annealing temperature caused a continuous vanishing of AA values. The vanishing had the same character for all the bands. By the way, the optical crystal characteristics after annealing were not the same as before irradiation.

In the CTII:YAG crystals several absorption bands caused by intracenter transitions in $\mathrm{Cr}^{3+}, \mathrm{Tm}^{3+}$ and $\mathrm{IIo}^{3+}$ ions are placed within the range of 240-900 $\mathrm{nm}$ of their spectrum. Under the irradiation by gamma quanta a wide AA band appears in the crystal spectrum within the range of 250-710 $\mathrm{nm}$ with some discrete absorption peaks at $255,320,385$ and $500 \mathrm{~nm}$. When the dosage level of gamma irradiation increases, the intensity of $\mathrm{AA}$ saturates. Comparison of the presented investigations with published in the paper [18], where radiation-induced coloring of Cr:YAG crystals (Cr concentration about 0.05 at.\%) was examined, shows that the AA bands close to $385 \mathrm{~nm}$ and $500 \mathrm{~nm}$ were measured in both cases. According to [18], the mentioned bands are connected with lattice defects caused by $\mathrm{Cr}^{3+}$ ions placed into the YAG structure. Presence of $\mathrm{Cr}^{3+}$ ions can explain a weak UV radiation susceptibility of CTII:YAG crystals (UV AA values of the order of $0.2 \mathrm{~cm}^{-1}$ ), which is very important for laser applications of the material after gamma irradiation (no changes in optical output after sequential multiple influence of the light pumping pulses).

Comparison of the results, concerning radiation-induced coloring of CTII:YAG, Er:YAG, Nd:YAG and pure YAG crystals, reveals presence of the common $A A$ bands at $\approx 250 \mathrm{~nm}, \approx 310 \mathrm{~nm}$ and $385 \mathrm{~nm}$, which can be attributed to the defects specific for the YAG structure (Figs. 1 and 2). Small variation in 


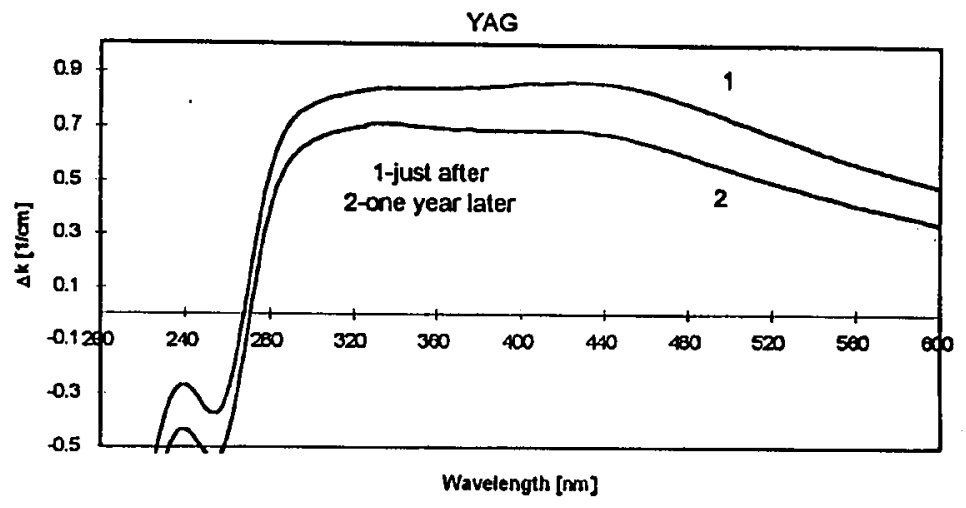

Fig. 1. Additional absorption bands of YAG crystal irradiated by gamma quanta just after irradiation (1) and one year later $(2)\left(\Delta K^{\prime}(\lambda)=(1 / d) \ln T_{1}(\lambda) T_{2}(\lambda), d\right.$ - sample thickness, $T_{1}, T_{2}$ - optical transmission before and after irradiation).

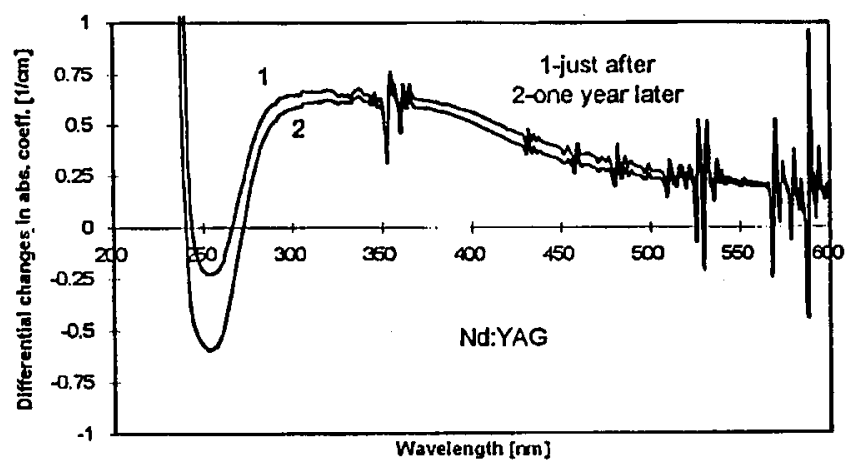

Fig. 2. Additional absorption bands of Nd:YAG crystal irradiated by gamma quanta just after irradiation (1) and one year later (2).

position of the absorption peaks may result from different concentrations of lattice defects caused by various dopants. Figures 1 and 2 show also the changes in $\Delta K$ values (AA bands) for YAG and Nd doped YAG crystals, after one year from gamma irradiation. One can see a small decrease effect in $\Delta K$ values after one year.

As was stated for Nd:YAG and Er:YAG crystals, CCs could be the result of defects of cation sublattice, oxygen vacancies or defects connected with ions of non-controlled impurities. Isochronous annealing of the irradiated samples of CTII:YAG crystals revealed that, unlike irradiated Er:YAG crystals, the CTII:YAG crystals returned exactly to their previous optical properties at the temperature of $500 \mathrm{~K}$. 


\subsection{Laser performance}

After gamma irradiation, the lasing properties of CTII:YAG and Er:YAG crystals are significantly changed. For the samples of CTII:YAG without preannealing (G21), the laser output energy increases 4 times immediately after irradiation. The changes have a stable character - the output laser energy is the same after even 80 days from irradiation and after many pulses of pump xenon lamp. The changes caused by gamma irradiation in the pre-annealed G32 CTH:YAG sample have a contrary nature. In this case, the output energy decreases more than 2 times. The sequential multiple influence of the light pumping pulses partially restores the optical output of the laser. The thermal annealing of this rod at $673 \mathrm{~K}$ gives different optical output than both before gamma irradiation and thermal annealing at high $(1773 \mathrm{~K})$ temperature.

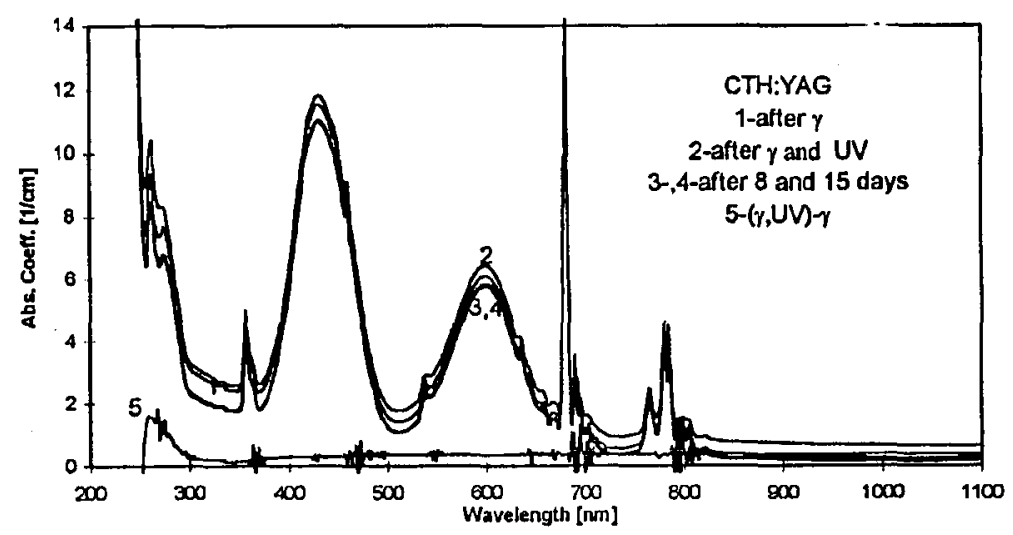

Fig. 3. Changes in gamma irradiated, preannealed CTH:YAG crystal $(0.85 \mathrm{~mm})$ after UV irradiation (15 pulses of xenon lamp with energy of $100 \mathrm{~J}$ and time interval of $15 \mathrm{~s}$ ) and 14 days later.

Figure 3 shows changes in absorption coeflicient of gamma irradiated preannealed CTH:YAG sample (thickness of $0.85 \mathrm{~mm}$ ) just after UV irradiation (15 pulses of $100 \mathrm{~J}$ energy with time interval of $15 \mathrm{~s}$ ) and 14 days later. One can see that after UV irradiation AA band with the peak at $260 \mathrm{~nm}$ and the constant AA (about $0.4 \mathrm{~cm}^{-1}$ ) band in the range of $300-1100 \mathrm{~nm}$ arises. 14 days later absorption coefficient becomes smaller than before UV irradiation. After each UV pulse absorption coefficient of gamma irradiated, preannealed CTH:YAG crystal, increases.

The increase in the laser output energy is also observed for Er:YAG crystal after influence of gamma quanta. At the pumping level of $205 \mathrm{~J}$, the output energy increases from $75 \mathrm{~mJ}$ for a non-irradiated crystal to $135 \mathrm{~mJ}$ for the sample irradiated with the dosage level of $10^{5} \mathrm{~Gy}$. The thermal annealing of the crystals after irradiation ( 3 hours at $673 \mathrm{~K}$ ) restores the initial characteristics of the laser. The subsequent gamma irradiation again increases the laser power efficiency. As is seen 


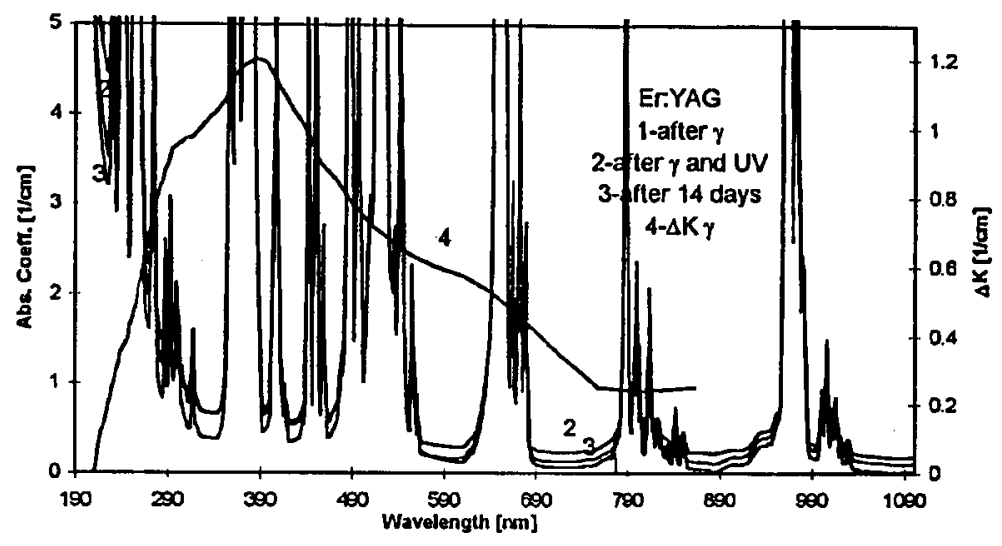

Fig. 4. Changes in gamma irradiated, preannealed Er:YAG crystal (1.05 mm) after UV irradiation ( 15 pulses of xenon lamp with energy of $100 \mathrm{~J}$ and time interval of $15 \mathrm{~s}$ ) and 14 days later.

from Fig. 4, corresponding changes in absorption coefficient after UV irradiation of Er:YAG sample $(1.05 \mathrm{~mm})$ are smaller than in the case of CTH:YAG crystal. The obtained results point to the direct influence of the CCs on the processes of formation of the population inversion of the laser levels of Er:YAG and CTH:YAG crystals.

In the non-annealed CTH:YAG crystal, a great concentration of different types of genetic (growth) defects can be found, which significantly decrease the laser efficiency. $\Lambda \mathbf{s}$ was shown earlier [3], after gamma irradiation of the crystals with garnet structure, rearrangement and recharging of the defects takes place, causing the change of the efficiency of pumping energy transfer to the emitting centers and increase in the optical output. For G32 sample, having reduced concentration of the growth defects due to high temperature annealing, the color centers emerging during gamma irradiation increase the active losses of the laser (increase in the value of generation threshold).

In the case of Er:YAG crystals, the emerging color centers, to our mind, may fulfill the function of sensibilizators, providing the increase in the pumping efficiency. In the Er:YAG crystals, the pump radiation excites ${ }^{4} S_{3 / 2}$ level $(\approx 550 \mathrm{~nm})$ and then (in the way of nonradiative recombination) ${ }^{4} I_{11 / 2}$ level, from where a radiative, laser transition to ${ }^{4} I_{13 / 2}$ level takes place.

Comparison of the AA spectra with the absorption spectrum of $\mathrm{Er}^{3+}$ ion [10] shows that the AA bands are superimposed with the most intensive bands corresponding to the transitions from the main state ${ }^{4} I_{15 / 2}$ to the multiplets of ${ }^{2} H_{9 / 2}$, ${ }^{2} H_{11 / 2}$ and ${ }^{4} F_{9 / 2}$ through which the laser pumping takes place and the sensibilization may occur according to the scheme presented in Fig. 5 (nonradiative energy exchange between color centers and above mentioned multiplets of $\mathrm{Er}^{3+}$ ions).

In the case of CTII:YAG crystals, the pumping process is completely different and much more complicated [19]. Comparison of the AA spectra with the absorption spectrum of CTH:YAG crystal shows that a gamma radiation creates 

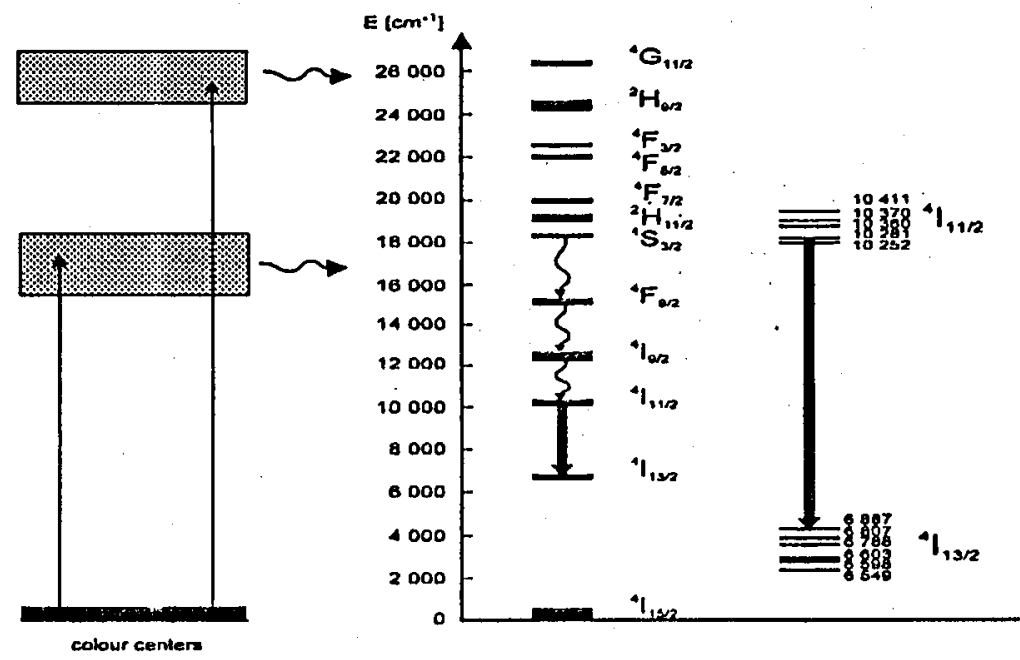

Fig. 5. The scheme of energy transfer from color centers to $\mathrm{Er}^{3+}$ ions of Er:YAG crystal.

in these crystals the CCs which increase absorption efficiency (near $\mathrm{Cr}^{3+}$ ion transitions at 430 and $600 \mathrm{~nm}$ - it can be seen especially from UV AA spectra [10,11]) and efficiency of exciting energy transfer between $\mathrm{Cr}^{3+}, \mathrm{Tm}^{3+}$ and $\mathrm{II}^{3+}$ ions.

It should be noted that, for the lasers emitting in 2-3 $\mu \mathrm{m}$ range, the passive losses due to the absorption of the color centers are absent because of great spectral distance between the lasing wavelength and the bands of additional absorption.

For Nd:YAG crystals the color centers absorption bands are also well superimposed with the most intensive bands of pumping $\left({ }^{4} I_{9 / 2} \rightarrow{ }^{2} G_{9 / 2},{ }^{4} G_{7 / 2}\right.$, ${ }^{2} G_{7 / 2}$ and ${ }^{4} G_{3 / 2}$ ). However, after gamma irradiation the laser output energy is decreased [5]. This fact may be accounted for circumstance that in Nd:YAG crystals, side by side with possible process of sensibilization by energy transfer from CCs to $\mathrm{Nd}^{3+}$ ions, the passive losses in lasing wavelength significantly increase [5].

\section{Conclusion}

After gamma irradiation of Er:YAG, Nd:YAG and CTII:YAG a wide complex of $A A$ bands appeared. These bands are connected with, stable at room temperature, CCs caused by gamma-induced recharging of growth defects, which may be non-controlled impurities of $\mathrm{Fe}$ ions, oxygen vacancies or defects of cation sublattice. In Er:YAG crystals CCs may play the function of sensibilizators providing the increase in the pump absorption efficiency $\left(\eta_{\mathrm{a}}\right)$ - by increase in population of ${ }^{4} F_{9 / 2},{ }^{2} I_{9 / 2}$ and ${ }^{2} H_{11 / 2}$ levels (Fig. 5), and optical output of laser at $\lambda=2.94 \mu \mathrm{m}$. In the CTII:YAG crystals sensibilization process is more complicated and needs more investigations.

\section{References}

[1] L.G. Karaseva, N.J. Konstantinov, V.V. Gromov, Radiat. Phys. Chem. 26, 723 (1985) (in Russian). 
[2] P.K. Habibulajev, I.R. Biedilov, H.B. Bejsembajeva, Radiationally Aclivated Process in Solid-State Lasers, FAN, Taszkient 1988, p. 316 (in Russian).

[3] A.O. Matkowski, D.Yu. Sugak, S.B. Ubizski, O.I. Shpotiuk, E.A. Chernyj, N.M. Vakiv, V.A. Mokshycki, Influence of Ionizing Radiation on Optoelectronic Materials, Svit, Lvov 1994, p. 212 (in Russian).

[4] N.A. Malov, A.I. Riabov, S.P. Nasielski, T.N. Toropkin, E.M. Svom, I.F. Usoltsev, Kvantov. Elektron. 10, 1067 (1983) (in Russian).

[5] T.S. Rose, M.S. Hopkins, R.A. Fields, IEEE J. Quantum Electron. 31, 1593 (1995).

[6] M.R. Biedilov, H.B. Bejsembajeva, M.S. Sabitov, Kvantov. Elektron. 21, 1145 (1994) (in Russian).

[7] M.Kh. Ashurov, E.V. Zharikov, V.V. Laptev, Sov. Phys. Dokl. 282, 1104 (1985) (in Russian).

[8] Z. Jankiewicz, J. Szydlak, W. Zhendzian, Elektronika 3, 7 (1993) (in Polish).

[9] E.V. Zharikov, V.I. Zhekov, T.I. Murina, V.V. Osiko, A.M. Prokhorov, E.I. Timoshechkin, Kvvantov. Elektron. 3, 589 (1976) (in Russian).

[10] S. Kaczmarek, A.O. Matkowski, Z. Mierczyk, S. Kopczyński, D.Yu. Sugak, Z. Frukacz, Opto-electron. Rev. 3/4, 74 (1995).

[11] S. Kaczmarck, Z. Mierczyk, K. Kopczyński, A.O. Matkowski, D.Yu. Sugak, Z. Frukacz, in: Proc. Int. Conf. on Intermolecular Interactions in Matter, Lublin 1995, Eds. K. Sangwal, E. Jartych, J.M. Olchowik, Technical University of Lublin, Lublin 1995, p. 134.

[12] A.N. Alpatev, M.Kh. Ashurov, E.V. Zharikov, A.I. Zagumienny, S.P. Katin, T.B. Lutc, I.R. Rustamov, W.A.Smirnov, A.F. Umyskov, I.A. Shcherbakov, Kvantov. Elektron. 18, 166 (1991) (in Russian).

[13] Z. Frukacz, Z. Mierczyk, Mater. Elektron. 22, 69 (1994) (in Polish).

[14] Z. Frukacz, J. Kisielewski, Z. Mierczyk, W. Szyrski, W. Zhendzian, Opto-electron. Rev. 1, 117 (1993).

[15] Z. Frukacz, T. Lukasiewicz, M. Malinowski, Z. Mierczyk, Proc. SPIE 2373, 74 (1995).

[16] A.I. Riabov, W.E. Kritska, V.M. Sorokin, Neorgan. Mater. 27, 2172 (1991) (in Russian).

[17] N.S. Stelmakh, A.I. Riabov, G.N. Pirogova, Neorgan. Mater. 28, 400 (1992) (in Russian).

[18] Kh.S. Bagdasarov, L.B. Pasternak, B.K. Sevastianov, Kvantov. Elektron. 4, 1702 (1977) (in Russian).

[19] S.R. Bowman, M.J. Winings, B.C.Y. Auyeung, J.E. Tucker, S.K. Searles, B.J. Feldman, IEEE J. Quantum Electron. 27, 2142 (1991). 